\title{
1. Intellectual property and sustainable markets: introduction
}

\section{Ole-Andreas Rognstad and Inger B. Ørstavik}

\section{FROM THE EDITORS}

The idea to investigate intellectual property and sustainability in a broader, market-based context was fostered within the Department of Private Law at the University of Oslo. In discussions with colleagues working within the fields of natural resources law, company law and intellectual property (IP) law, we observed that we all deal with many of the same overreaching challenges relating to sustainability and development in a broader sense. The approaches to the role of the law in solving these challenges, however, varied greatly. Nevertheless, a common denominator was the recognition of the need for society to tackle the challenges of securing sustainable development, and that sustainable development would depend on legal mechanisms for preserving knowledge and developing new knowledge. Furthermore, that those mechanisms, to contribute to both innovation and development of knowledge as well as sustainability, would likely have to be market-based and concrete. This book is the result of the discussions about the need to combine different fields of law in order to provide more depth and understanding to the topic of sustainability and IP law.

\section{SUSTAINABILITY AND IP}

The modern concept of sustainable development (SD) is often ascribed to the Brundtland report to the UN from 1987 but was then a rather toothless concept. It was defined as 'development that meets the needs of the present without compromising the ability of future generations to meet their own needs'. ${ }^{1}$ It has later been suggested that this definition 'should ... be redefined to "development that meets the needs of the present while safeguarding Earth's

See Chapter 4, fn. 5, infra. 
life-support system, on which the welfare of current and future generations depends". ${ }^{2}$ As such, sustainability refers to all policies and developments, as is also clear from the UN global goals for sustainable development (SDGs), the '2030 Agenda'. ${ }^{3}$ The 17 goals include diverse issues such as the ending of poverty and hunger and ensuring of healthy lives (goals 1-3), the ensuring of clean water and sanitation (goal 6), affordable and clean energy (goal 7), industry, innovation and infrastructure (goal 9) and climate action (goal 13), but also more general goals such as gender equality (goal 5), peace, justice and strong institutions (goal 16).

The role of intellectual property rights (IPRs) in order to achieve the SDGs is hardly visible in the agenda ${ }^{4}$ (although it has been underscored elsewhere), ${ }^{5}$ at the same time as the importance of technology and technological development are highlighted throughout. This emphasizes not only the importance but also the complexity and the ambiguity inherent in and surrounding IPRs as tools for promoting SD as well as pointing to possible supplements and alternatives to IP protection in furthering innovation to the benefit of SD. In this respect, simplistic approaches - such as a polarized discussion as to whether IPRs hinder access to resources or foster innovation essential to SD - should be avoided at least on a general level since the role and the impact of IPRs may differ in a multitude of respects.

The purpose of this book is to demonstrate and discuss the multi-faceted aspects of IP in relation to SD. Thus, the contributions evolve around several different SDGs as well as highlighting a whole range of different angles as to how IP can play a role in SD policy. In this respect, a general and universal approach is hardly possible. On the contrary, it is important to take account of 'local needs, national interests, technological capabilities and institutional capacities, and public health conditions', because 'the differences in economic conditions, imitative or innovative capacities, research and development productivities, and availability of human capital, [may imply that] an innovative model that works well in one country may not suit the needs and interests of another' ${ }^{6}$ Thus, although SD is a global phenomenon and responsibility, there

\footnotetext{
2 David Griggs et al. 'Sustainable Development. Goals for People and Planet', 495 Nature (2013), 305-330, 306.

3 'Transforming our World: The 2030 Agenda for Sustainable Development', United Nations - Sustainable Development knowledge platform, https://sustainabled evelopment.un.org/post2015/transformingourworld (accessed 23 August 2015).

4 See Chapter 2, infra.

5 See Chapter 3, infra.

6 Peter K. Yu, 'Realigning TRIPS-plus Negotiations with UN Sustainable Goals', Chapter 3 in this volume, section 3.2 infra.
} 
are indeed problems concerned with seeking global or universal solutions to the IP/SD interface.

Overly simplified, sustainability is about choice of priorities, choosing the sustainable over the non-sustainable solutions, and demanding of all policies, investments and developments that they do not compromise the needs of future generations by contributing to SD.

\section{SUSTAINABLE MARKETS: A CONTEXTUAL APPROACH TO IP AND SUSTAINABILITY}

\subsection{IP in Context}

Moving into the IP/sustainability interface from the perspective of IP law enables us to look more closely at the role of IPRs in SD. IPRs provide incentives for private investment in innovation and creation. The legal right creates an exclusive position not otherwise inherent in knowledge and provides incentives to invest in innovation at a time when the result of the innovative/creative effort is still uncertain. However, the legal regulation of IPRs is general with regard to the outcome of innovative and creative processes and provides little flexibility to direct investments towards sustainable technologies and knowledge over other technologies.

The objectives of IPRs are the promotion of innovation and development of new knowledge. The basic rationale for awarding individuals exclusive rights to inventions or works of art or literature etc. is that innovation and creation lead to new knowledge to the benefit of society. On a theoretical and abstract level, it could be argued that innovation and new knowledge contribute to SD, as it enables us to make better, more sustainable choices based on enhanced knowledge. That assumption, however, requires that the context in which IPRs function incentivizes sustainable choices. IPRs are designed to work as legal instruments within an environment comprising other legal, factual and social mechanisms. A legal discussion of IPRs is incomplete if it is not contextual.

IPRs have proven to be robust against time and societal development, something that may also be partly ascribed to their contextual nature. International treaties regulating IPRs have existed for more than 130 years, and although corresponding national legal systems vary in tradition and experience, IPRs have survived revolutionary technical and societal developments. Apart from the fact that the international regime itself may serve as a barrier for radical reforms, as changes require consensus, IPRs function within the current and local legal, factual and social context, contributing to knowledge development within those trends.

The contextual nature of IPRs as well as the overarching nature of sustainability makes the discussion of IP and sustainability multi-faceted and diverse, 
as is reflected in this book. The contributions discuss different SDGs, either from a broader perspective, ${ }^{7}$ or individually. Several of the following chapters discuss environmental concerns and climate change related issues (pertaining to SDGs 7, 12 and 13 in particular). Other chapters deal with public health concerns, in particular in developing countries (pertaining to SDGs 1-3) ${ }^{8}$ and cultural sustainability. ${ }^{9}$ Furthermore, several of the contributions touch upon the promotion of inclusive and sustainable industrialization and the fostering of innovation (SDG 9).

As IP interrelates with the goal of SD, a number of different legal issues arise. While not writing off radical changes to IP law as a means to promote $\mathrm{SD}$, this book primarily discusses the interrelation between IP and other legal fields or issues, thereby contributing to a discussion of the role of IP in promoting and ensuring that development is sustainable. The first two chapters take an overarching approach to IP and sustainability, discussing the appropriateness of the international legal IP framework to deal with SD. Chapter 4 discusses the concept of cultural sustainability, its impact and importance. Chapters 5 and 6 take an IP integrated approach, discussing the openness of IP law to include sustainability considerations in the concrete application of the law. Chapters 7, 8 and 9 ask how IPRs and IP policy can contribute to SD, in particular, in the current technological environment and how other areas of law and policy are interrelated with IP law. Finally, Chapter 10 discusses alternative models for fostering innovation to the benefit of SD. There are past lessons learned, including what seem to be success stories, and future perspectives on how to improve on the IP/sustainability interface.

The diverse angles taken and problems discussed show the importance of examining IPRs in a legal, factual and societal context, especially when discussing the overarching goal of sustainability. This is not one, but many discussions. There are also important background trends in the context of IP that are merely touched upon in this book but are nevertheless significant.

First, there is the traditional silo approach of law and policymakers to IPRs as innovation policy and sustainability as environmental and development policy. On an international level, IPRs are remarkably non-addressed in the UN sustainability goals or in important international legal instruments dealing with environmental issues, such as the Paris Agreement. While not surprising, as there are only so many compromises between diverging interests that can be aligned within one set of international treaties or instruments, ${ }^{10}$ the trend is to

Chapter 2, infra.

Chapter 3, infra.

Chapter 4, infra.

10 See, for example, Abdel Ahmed Latif, 'Intellectual Property Rights and the Transfer of Climate Change Technologies: Issues, Challenges and Way Forward', 15 Climate Policy (2015), 103-126. 
under-communicate the interrelation between the various areas of law relevant to achieve the SDGs.

At the level of national law, the same divide can be found. This book makes an important contribution to the international debate on the IP and sustainability interface by pointing to the interrelation between IP law and other areas of law, when considering how IPRs may play a role in achieving the SDGs. As the concept of sustainability is holistic, this work should also impact the debate within the different legal fields.

Despite this divide in the regulatory framework, there are numerous initiatives for cooperation between policymakers on international, ${ }^{11}$ regional and national levels, as well as an emerging willingness of lawmakers to include sustainability in market-based regulation. ${ }^{12}$ This book provides useful insights for these discussions.

Second, market dynamics form a factual context for the role that IPRs play in innovation processes and in the market. In some markets, IPRs do not appear necessary to provide incentives to develop new technology and bring it to the market. The solar PV industry is an example. Licence fees are only a small part of the costs in the industry value chain, indicating that IPRs are not a significant source of income for developers and producers in the solar PV industry. In wind technology, on the other hand, patent rights are highly concentrated, in that access to IPRs is likely to form a significant barrier to entry. The role that IPRs play for the development of technology and for market dynamics differs fundamentally in diverse markets.

In some markets, technology risks are high, as in markets with extreme network effects (such as telecommunications) and, as discussed here, in energy supply, i.e. the development of the grid. In these markets, there can be only one or a select few technology winners. When the risk of developing technology that is immediately obsolete is high, IPRs can be necessary. The discussion then turns to how other legal instruments work together with IPRs to facilitate efficient technology development and deployment. The development of technical standards is one aspect of this.

Finally, society is in constant development, and the role of IPRs is affected by trends and social innovation. An important current social development is the transformation of the passive consumer into a 'prosumer' who is actively

${ }^{11}$ Cf. the interesting cooperation between the European Patent Office (EPO) and the International Energy Agency (IEA), see https://www.iea.org/news/epo-and -iea-team-up-to-shed-light-on-trends-in-sustainable-energy-technologies (accessed 29 October 2020).

12 See on a European level, the European Green Deal launched by the EU Commission, see https://ec.europa.eu/info/strategy/priorities-2019-2024/european -green-deal_en (accessed 29 October 2020). 
participating in the market, either by 3D printing their own medical equipment or by delivering excess energy from their solar panel into the electric grid. Two-, or multi-sided business models are rapidly becoming the new standard in many economic areas. Multi-sided business models are important from a sustainability perspective, as they reduce transportation, facilitate reuse and recycling, and enable faster roll-out of renewable energy. The interface between IPRs and sustainability includes questions relating to the effects and limitations of IPRs: Do they facilitate or hinder the development of new business models? Are IPRs necessary as an incentive to innovate in these types of markets?

To conclude, the role of IPRs in developing sustainable markets is multi-faceted and partly ambiguous and dependent on how the potential to reconcile the traditional justifications of and approaches to IPRs with sustainability goals is exploited, or for that sake, the potential to reform IP law if necessary. In this book, various aspects of these questions are addressed and discussed.

\subsection{Sustainable Markets: The Contextual Approach in this Book}

The book begins with an overarching discussion of the relationship between IP law and the UN SDGs by Hans Morten Haugen. In his contribution, he addresses the divide between IP law and the international policies under the UN SDGs and provides a discussion of possible reasons for this divide. The chapter observes that IP has not been central in the formulation of the UN SDGs. Only one reference to IP is made in the 2015 Transforming Our World resolution, introducing the 17 SDGs (UN 2015, objective 3b), namely on the flexibilities to protect public health as allowed for in the TRIPS Agreement. Numerous reports under the Millennium Project analysed the role of science and technology in fulfilling the SDGs, criticizing the functioning of the present IP system in different ways. Based on the strong links between a well-functioning IP system and successful application of science and technology for sustainable development, the chapter presents five hypotheses in order to explain why IP is not highlighted in the context of the SDGs. These hypotheses are tested by analysing UN-wide processes relating to technology, processes within the World Intellectual Property Organization (WIPO), and TRIPS flexibilities.

Chapter 3, authored by Peter K. Yu, discusses more closely the interrelation between the SDGs and the TRIPS regime, with particular emphasis on the challenges faced by developing countries in promoting and fulfilling the SDGs. He observes that the UN SDGs were adopted at a time when countries were busy negotiating TRIPS-plus bilateral, regional and plurilateral agreements. The chapter explores how developing countries could attain more success by 
realigning TRIPS-plus intellectual property negotiations with the SDGs. It begins by discussing the intersection between the SDGs and the development of the intellectual property system - at both the domestic and international levels. The chapter then outlines the direct and indirect impediments to the promotion and fulfilment of the SDGs that have been generated by the recent and ongoing negotiations for TRIPS-plus trade agreements. These agreements include the Anti-Counterfeiting Trade Agreement, the Trans-Pacific Partnership Agreement (now the Comprehensive and Progressive Agreement for Trans-Pacific Partnership) and the proposed Regional Comprehensive Economic Partnership Agreement. In view of the potential dangers and complications caused by TRIPS-plus IP negotiations, this chapter concludes by identifying six distinct strategies that developing countries may deploy to ensure greater promotion and fulfilment of the SDGs.

In Chapter 4, Daniel J. Gervais discusses cultural sustainability as reflected in several of the SDGs. He notes the interrelationship between cultural and environmental sustainability and emphasizes that cultural sustainability is about the empowerment to develop and propagate values in a given society, including via art, literature and information. The chapter discusses in particular two vehicles that can contribute to human progress, the creation, dissemination and availability of Socially Responsible News (SRN) and literary and artistic creations. The allegation is that the continued role of those two vehicles is in serious peril, in that their very existence depends on factors wrongly taken for granted: the existence of professional creators, including journalists, on the one hand, and of organizations that support them such as publishers and news organizations, on the other. The author examines the situation of current markets for SRN and literary and artistic productions, and in particular the disruption caused by the shift to a few major digital platforms. Reform suggestions are made in relation to one important IP policy level: copyright, including a possible overhaul of the norms contained in the most important copyright treaty, the Berne Convention.

In Chapters 5 and 6, the authors take a concrete and national or regional view on how sustainability can be integrated into IP law. The preface for the discussion is the societal demand for more sustainability in the trade in goods, and the call that the law should contribute to repair and reuse of goods rather than mere consumption under SDG 12. Trade mark and patent rights do provide an exclusive right to ensure that the right holder recaps the full worth of the first sale of the product, but the actual scope of the right has not been discussed in the context of sustainability. Both contributions ask whether there is elasticity in patent and trade mark law to include a sustainability perspective in the application of national and regional law.

In Chapter 5, Taina Pihlajarinne examines repair activities and use of recycled materials from European patent and trade mark law perspectives. 
The chapter focuses on two examples that demonstrate a strong property right impact on recycling efforts. The first is the consideration of normal lifespan in the repair or reconstruction dichotomy in the patent context, and the second involves the possibility to use trade marks in so-called upcycling activities. The chapter assesses the structures and interpretations of exclusive rights as impediments to the circular economy achieving its full potential in terms of repairing products or re-using materials. The author suggests that a concept of a 'sustainable lifespan' could be adapted into the IPR framework. The dichotomy between infringement and repair and reuse should be realigned around a 'normal, sustainable lifespan for that particular product' or an 'environmentally friendly lifespan' to cohere with a sustainable trade in goods.

Following the direction of Pihlajarinne's contribution, in Chapter 6 Ole-Andreas Rognstad discusses a judgment from the Norwegian Supreme Court where the Court rejected the relevance of sustainability arguments where iPhone screens were imported from Hong Kong to Norway for repair purposes. The screens were originally provided with Apple logos affixed without the consent of Apple Inc. but were de-branded with a removable ink marker prior to import into Norway. The Supreme Court found that the import infringed Apple's trade mark right, and held that competition and sustainability arguments were not relevant since the outcome only concerned trade mark use and not the use of screens. The Court nevertheless discussed whether the import negatively affected trade mark functions, a question answered in the affirmative. In the author's opinion, the Court's reasoning is based on postulates rather than any real assessment of harm to the trade mark, making the rejection of the relevance of sustainability arguments off target. The chapter points out that there is potential inherent in the doctrine of trade mark functions to take sustainability concerns into consideration, provided that more solid evidence is required for finding that these functions are harmed.

Chapters 7 to 10 discuss the process of innovation from various angles. Recognizing that innovation is paramount to promote and fulfil the UN SDGs, IP law alone does not support innovation, as the efficiency of IP law is largely dependent on other law and policy.

The primary objective of IPRs such as patents, designs and copyright is to provide incentives to invest in innovation and creation. However, the exclusive rights in themselves are hardly adequate to guarantee access to capital for innovators and creators. In Chapter 7, Janice Denoncourt discusses the role of IPRs in financial regulation, suggesting that financial regulation should facilitate a financial market better adapted to providing financing for innovation. Green finance (climate change mitigation and adaptation and related risks) and blue finance (to support ocean resilience) depend on innovation, so there is arguably a more prominent role for IPRs in sustainable finance initiatives. The chapter critically examines the activity of the Basel Committee on Banking 
Supervision (BCBS) and the Basel Accords ${ }^{13}$ bank asset classification system as applied to intangible assets as loan security (collateral). ${ }^{14}$ Through an interdisciplinary traditional law and qualitative analysis, the author builds an exploratory case to support a new approach to the prudential regulation capital adequacy ratios (CARs) when transactions involve registered granted IPRs, such as patents, as loan security. The author evaluates why and how registered IPRs could be an important component of the evolving sustainable finance market with a role to play in unlocking critical innovation financing.

In Chapter 8, the discussion of IP moves from the context of financial markets to energy markets. Inger B. Ørstavik discusses how the transition from fossil to renewable energy, i.e. the fulfilment of SDG 7, is dependent on innovation in renewable energy technologies. The chapter uses the solar PV industry as an example, arguing that a coherent approach to energy policy and innovation policy is necessary due to the externalities of the technology neutrality of patent law. Patent law inadequately incentivizes innovation in renewable energy technologies over fossil technologies. Furthermore, patent law does not stimulate sustainability in the renewable energy industry as such, evidenced by the reliance on coal-fired utilities in the production of solar PV systems. The author argues that energy or environmental policies that support sustainability in the dynamics of the market will indirectly include sustainability in patent law, as market dynamics are integrated into the normative rationale of patent law. The chapter discusses how such policies can support the functions of patent law, driving innovation in renewable energy technologies and contributing to ensure that energy and industry markets are sustainable. The discussion concretizes an example of the argument made above, that a discussion of sustainability must take a holistic view.

Chapter 9 deals further with the energy market and ties into the societal trend that the supply of electricity is no longer a traditional one-sided supply, but a multi-sided business. An important development is the transition to a 'Smart Grid'. Joel B. Eisen and Kristen Jakobsen Osenga discuss how the United States is transforming its electric grid with Smart Grid initiatives that aim to overhaul the grid with modern, digital technologies, incorporate new resources, reduce carbon emissions, and provide consumers with new options for generating, using, conserving and transferring electricity. Interoperability standards have been recognized as central to the Smart Grid in the US. A fast-track process was established to develop and approve these standards,

13 The BCBS was established in 1974 and issued the first Basel Accord in 1988 followed by the second, third and fourth of the Basel Accords over the next two decades.

14 Although they have no legal force, the Basel Accords are voluntarily adopted by member nations, see https://www.bis.org/bcbs/about/overview.htm? $\mathrm{m}=3 \% 7 \mathrm{C} 14$ \%7C573 (accessed 29 October 2020). 
working in conjunction with standards developing organizations (SDOs). The authors find that patenting and standard setting are complementary and foster competition for speedier innovation. To protect companies other than patent holders, SDOs require that a patentee disclose any patents that are necessary to practise the standard and provide a licence under [fair], reasonable, and nondiscriminatory ([F]RAND) terms. This has struck an appropriate balance between the need for rapid standards development and the goal of IP protection, instrumental in the development of a centralized Smart Grid in the US.

In the final chapter, Catherine Banet explores innovation policy beyond IP law and discusses the concept of 'open innovation' in the context of the energy transition and the development of low carbon technologies. The chapter explores the interaction between energy law and IP law in the ecosystem of the energy sector, especially in relation to the development of low carbon technologies. The chapter includes a discussion of open innovation as a concept and the involvement of IPRs, providing a concrete analysis of how the development of low carbon technologies is increasingly reliant on open innovation models. The author also considers the implications of open innovation models on IP law and energy market regulation. The discussion provides the basis for reflections on the inter-regulation between IP law and energy law. This final chapter returns the discussion to the agenda for this book: the contextual and market-based analysis of IP and sustainability.

\section{SUSTAINABLE MARKETS: A REALISTIC AND HOLISTIC APPROACH}

Earlier in this introductory chapter, we pointed out that the discussion of IPRs and sustainability must take into account local needs, interests and overall differences, especially along the highly contentious axis of developing vs developed countries. The discussions in this book show that by taking a contextual and market-based approach to IP and sustainability, the discussion of how IPRs may include or promote sustainability becomes more nuanced. We believe that a holistic approach, where IPRs are discussed in a market context and the requirement for sustainability is applied to the market outcome, will provide a more realistic approach. However, one should not be afraid to introduce radical reform proposals in the IP field in order to achieve sustainability goals. To use Drahos' words: 'The world should not enter its longest night of crisis with globally extractive intellectual property institutions. ${ }^{15}$ And bearing in mind the challenges that the Covid-19 pandemic have posed to the global

15 Peter Drahos, 'Six Minutes to Midnight - Can Intellectual Property Save the World?', in Kathy Bowrey, Michael Handler and Dianne Nicol (eds), Emerging 
society, there might - as one commentator has put it - be 'a need to translate the collective solidarity we experience today into legally enforceable measures that balance patent protection and global access'. ${ }^{16}$ This statement resonates with other IPRs and sustainability concerns as well.

Challenges in Intellectual Property, Oxford University Press: Australia (2011), Chapter 2.

16 Geertrui van Overwalle, 'Will Covid Patents Save the World?', 69 GRUR Int. (2020), 883-884, 884. 